\begin{tabular}{|c|c|c|}
\hline 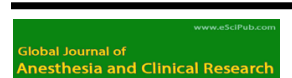 & & $94 y^{2}$ \\
\hline 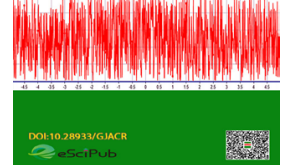 & $\begin{array}{l}\text { Global Journal of Anesthesia and Clinical Research } \\
\qquad(\text { ISSN:2637-6245) }\end{array}$ & thes \\
\hline
\end{tabular}

\title{
Incidence of Hypotension and Associated-risk Factors in Epidural Anesthesia With 2\% Lidocaine and Epinephrine During Elective Cesarean Section, Efficacy and Safety Assessment
}

\author{
Bizimana Prudence, Minghao Liu, Bin Wang \\ Department of Anesthesiology, first affiliated hospital, Chongqing Medical University, China
}

\begin{abstract}
Background: Cesarean section is a worldwide common surgery that requires anesthetic techniques. Many local anesthetics are being now used, but are associated with, dose- dependent and at different level, some side effects including toxicity. Hypotension was described as the first and threat side effect associated to neuraxial techniques. Despite many preventive strategies, it continues to challenge anesthesia providers around the world. Lidocaine was found to be less toxic compared with others commonly used and has been recommended for anesthesia procedures requiring large dose of local anesthetic including epidural anesthesia. The main purpose of this research was to determine the incidence of hypotension and identify the possible risk factors associated with it and thus, assess the efficacy and safety when lidocaine is applied together with epinephrine, in epidural anesthesia for elective cesarean delivery. Materials and methods: This retrospective observational institutional-based study, recruited 612 parturients who underwent elective cesarean section under epidural anesthesia with $2 \%$ lidocaine and $1 / 200000$ epinephrine, at 1st affiliated hospital of Chongqing Medical University in 2019. Exclusion criteria included any contraindication to elective cesarean section delivery, general anesthesia, baseline systolic blood pressure $<100 \mathrm{mmh}$ and $>140 \mathrm{~mm}$ hg, gestational age $<37$ weeks and $>42$ weeks etc. SPSS 26.0 version and different appropriated tests were used for statistical analysis. $P$ value $<0.05$ was accepted as statistically significant. $\mathbf{R e -}$ sults: The hypotension incidence was $13.2 \%$, and identified factors associated with it were Baseline Systolic Blood Pressure $<120 \mathrm{mmhg}$, gestational age $<40$ weeks, maternal body weight $\leq 60 \mathrm{~kg}$ and duration of cesarean delivery (surgery) $>45$ minutes. Conclusion: The variables in correlation with increased hypotension rate are baseline systolic blood pressure, gestational age, maternal weight, and surgery duration. $2 \%$ Lidocaine with epinephrine as adjuvant presented best outcomes towards both mother and neonates, was therefore efficacy and safe under the anesthetic conditions of our study.
\end{abstract}

Keywords: Hypotension, pain, epidural anesthesia, lidocaine, epinephrine, cesarean section

*Correspondence to Author: PROF. BIN WANG

Department of Anesthesiology, first affiliated hospital, Chongqing Medical University, Chongqing 400016, China

How to cite this article:

Bizimana Prudence, Minghao Liu, Bin Wang. Incidence of Hypotension and Associated-risk Factors in Epidural Anesthesia With 2\% Lidocaine and Epinephrine During Elective Cesarean Section, Efficacy and Safety Assessment.Global Journal of Anesthesia and Clinical Research, 2021, 4:9

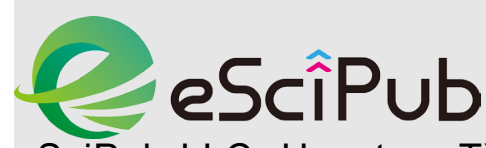
eSciPub LLC, Houston, TX USA. Website: https://escipub.com/ 


\section{INTRODUCTION}

Recent researches showed that more than 32\% [35\% in USA ${ }^{[1]} ; 32,5$ in Ethiopia, Africa ${ }^{[2]}, 32 \%$ in Thailand [3] of women, give birth under cesarean section [CS]. The trend is increasing ${ }^{[1]}$ and even reached $46 \%$ in China according to the results of a study published in $2016{ }^{[4]}$. Many cesarean deliveries [CD] are performed under neuraxial anesthesia using local anesthetics [LAs] ${ }^{[2]}$. These agents sis, dose-dependent and at different level, affiliated with dire side effects including fatal systemic toxicity via different mechanisms [6,7,9-12]. The special pregnancy's pathophysiology and the hypersensitivity of pregnant women to LAs ${ }^{[11,13]}$, put her in highrisk population for LAs systemic toxicity, which may happen with any route of administration, even more so, with a big dose-use like in epidural anesthesia [EPA] [14,15]. To minimize the occurrence of LAs systemic toxicity, lidocaine has been recommended for all anesthesia procedures requiring large amount of LAs including epidural anesthesia. Somatovisceral pain and severe hypotension during $C D$ under neuraxial anesthesia remain, whoever, a consistent challenge ${ }^{[5,8]}$ and a main preoccupation of anesthesia providers worldwide. Hypotension is still the most prevalent complication of CS [8,16,17]. Several underlying maternal and fetal redoubtable risks along with death, are associated with prolonged hypotension [17,18]. Indeed, cerebral hypoperfusion due to the sympathetic blockade may be responsible of nausea- vomiting and Mendelson syndrome, change in cardiac output/rate, while impaired placental perfusion leads to newborn hypoxia, acidosis and neurological damage [19-22]. Cardiorespiratory arrest and a possible death [23] is to be feared. It is then, highlighted that severe hypotension is a yardest side effect for being a cause of other dire complications. Although there are many variations, most researchers set up definitions of hypotension as a maternal systolic blood pressure [SBP] below $70 \%-80 \%$ considering the baseline or an absolute value of less than 80 -
$90 \mathrm{mmHg}$ to $100 \mathrm{mmHg}$ from baseline SBP or both ${ }^{[8,16]}$. So, there is not any consensus about clear criteria of hypotension during neuraxial anesthesia up to now. In our study, we considered severe hypotension as a value of SBP less than $90 \mathrm{~mm}$ hg based on several previous researchers considerations [8,18,28-30]. Though all preventive measurements taken, severe hypotension during CS under EPA is not absent as well as in combined spinal-epidural anesthesia technique for $C D$, and can jeopardize mother and his fetus ${ }^{[8,16,31]}$. To know predisposing factors of hypotension in obstetric EPA is a key and paramount step for preventing many side effects and providing a safe anesthesia in this area where many lives are impacted. A plethora of researches [2,3,15,24-27] conducted on anesthesia for CS assessed bupivacaine and ropivacaine outcomes with some few studies [2] identifying associated riskfactors to hypotension, but only after spinal anesthesia [SA] was performed for CS. At our knowledge, any similar study has been conducted when $2 \%$ lidocaine and epinephrine as additive, was applied in EPA. Corollary, the surgical anesthesia features of this LA may remain unknown by some anesthesia providers. We conducted, then, this clinical research in order to, mainly, determine the incidence of hypotension and identify possible risk factors associated with it, and assess the efficacy and safety of $2 \%$ lidocaine with epinephrine in epidural anesthesia for scheduled CD. As it is, exclusively, the LA employed for elective epidural CS in anesthesiology department of first affiliated hospital of Chongqing Medical University [CQMU]/China, we hypothesize that, $2 \%$ lidocaine with epinephrine has best maternal and neonatal outcomes with a little hypotension incidence, during the whole time of elective CS.

\section{MATERIALS AND METHODS}

Study design: Retrospective observational study

This study was approved by Ethical Review Committee of first affiliated Hospital of CQMU and has a registration number of "Research 
ethics in 2020 [2020-526]". First affiliated Hospital of CQMU is a tertiary and teaching hospital located in Chongqing city southwestern China. We searched anesthesiology department database targeting electronic medical records especially anesthesia records, for getting original data of planned $C D$ performed under EPA with lidocaine $2 \%$ and epinephrine $1 / 200,000$. Data were collected with objectivity and rationality for this study, in the spirit of Helsinki declaration as reviewed in 2013. 612 clients who underwent CS under EPA of the period from January $1^{\text {st }}$ to December $31^{\text {st }}, 2019$; and fulfilled our inclusion criteria, were retrospectively reviewed. The methodology in this study was based on the international guidelines for observational Studies according to Strengthening the Reporting of Observational Studies in Epidemiology [STROBE], 2020 statement [see file in Supplementary material/STROBE checklist]. The detailed parameters of patient demographic data [Age, Maternal body weight, Maternal height, BMI, NYHA, ASA status, Parity, Gravidity, Term], surgical data [starting and end time of surgery, fetal extraction time, fetal sex, estimate blood loss], anesthetic data [amount \& time of $1^{\text {st }}$ and $2^{\text {nd }}$ dose, $3^{\text {rd }}$ dose, $4^{\text {th }}$ dose of LA, vasoconstrictors, opioid agents, muscle relaxion, hypnotic drug, sensory level of blockade, parturients' position and site of epidural puncture] and Apgar scores at $1^{\text {st }}, 5^{\text {th }}$ and 10 min were computerized and have been collected, from $1^{\text {st }}$ January to $30^{\text {th }}$ April 2021, using a preestablished data collection sheet. General perianesthesia management was electronically reported on forensic documents: parturients arrived in operating room with an indwelling 18gauge or 20 peripheral intravenous line already placed, with an ongoing normal saline or ringer's lactate. For each patient; oxygen supplementation $3 \mathrm{ml} / \mathrm{min}$ was given from Dräger anesthetic machine using a facial mask, monitoring of peripheral oxygen saturation was systematically performed, non-invasive blood pressure, and electrocardiogram were recorded continuously before, during and after skin incision until the end of surgery. It was recorded that left uterine displacement was initiated when SBP dropped under $100 \mathrm{~mm} \mathrm{hg}$. The lowest systolic, diastolic blood pressure and heart rate were noted on anesthesia record. When hypotension occurred [SBP $<90 \mathrm{mmhg}$, phenylephrine and/ or ephedrine, were used to treat it. The anesthesia onset time was recorded and collected.

Hypertonic drug and dexamethasone were given to each parturient. No prophylactic vasoactive agent given was reported.

Inclusion criteria: All admitted woman in surgery theatre in $1^{\text {st }}$ affiliated hospital of CQMU for elective cesarean delivery in good health condition: normal SBP [100 $\leq$ SBP $\leq 140 \mathrm{mmhg}$, normal NYHA, ASA physical status no more than 3 , singleton pregnancy, gestational age between 37 and 42 weeks [37 term $\leq 42$ ], without any condition contraindicating epidural anesthesia.

\section{Exclusion criteria: General anesthesia,} multiple pregnancy, $\mathrm{SBP}<100$ or SBP $>140 \mathrm{~mm}$ hg, pregnancy term $<37$ or $>42$ weeks, NYHA high than 2 class, ASA physical status more than 3 , Other conditions contraindicating elective cesarean delivery.

Data extraction: As it is a retrospective study, and sometimes, important information may not be reported on anesthesia record, and to avoid bias, two parameters helped us to know if it was been severe hypotension: lowest blood pressure or/ and dose of vasoconstrictors given. We have considered severe hypotension for parturients who received more than 50 micrograms of phenylephrine or more than 6milligrams [more than one intravenous injection] of ephedrine as vasopressor, and parturients for whom SBP dropped under $90 \mathrm{mmhg}$. For somato visceralpain during surgery, we confirmed its occurrence if we saw hypnotic and/or opioids [fentanyl, sufentanil, or remifentanil] administered after fetal extraction. As supplementary endeavors to minimize bias, two authors handled this task in different time and compared our data in office. If any heterogeneity, we searched again database

GJACR:https://escipub.com/global-journal-of-anesthesia-and-clinical-research/ 3 
together. Persistent discord was solved out by consensus after discussion.

Statistical analysis: We coded and recoded all parameters and variables into SPSS 26.0 version to perform appropriate statistics for description of the data's pattern. We expressed our data like mean, median, Standard Deviation [SD], minimum, maximum or number [\%] as appropriate. All parametric and non-parametric data were tested for normal distribution and appropriate statistical analysis followed. $P$ value less than 0.05 was used to identify statistical significance. To assess the association between two categorical variables in a univariable analysis, chi-square test was used along with Odds Ratio [OR] and its 95\% Confidence Interval $[\mathrm{Cl}]$. Multivariate logistic regression analysis was used in purpose to determine the effect of each independent variable on binary dependent variables after adjusting for the other independent variables, and thus, identity the relevant risk- factors for severe hypotension. Results which show relevant factors associated with severe hypotension were displayed in a categorical table as Adjusted Odd Ratio [AOR] and $95 \% \mathrm{Cl}$.

\section{RESULTS}

After thoroughly searching relevant documents and all anesthesia records of parturients who underwent CS in the whole year of 2019, a total of 2944 women have been counted. 1752 women [59.51\%] underwent CS with GA and were at priori excluded, while 1192 [40.5\%] have been identified to be elective CS performed under EPA with 2\% lidocaine and epinephrine. Among these 1192 woman, 280 [23.5\% of the 1192] were excluded for either incomplete data or administration of some anesthetic drugs before fetal extraction while 35 parturients were excluded for multiple pregnancies. 116 parturients were also excluded because of their BSBP below $100 \mathrm{mmh}$ or over than $140 \mathrm{mmhg}$. 140 were excluded for preterm or over term [37> term $>42$ weeks]. Finally, 612 [51.3\% of the all CDs under EPA] parturients have been retained for statistical analysis.

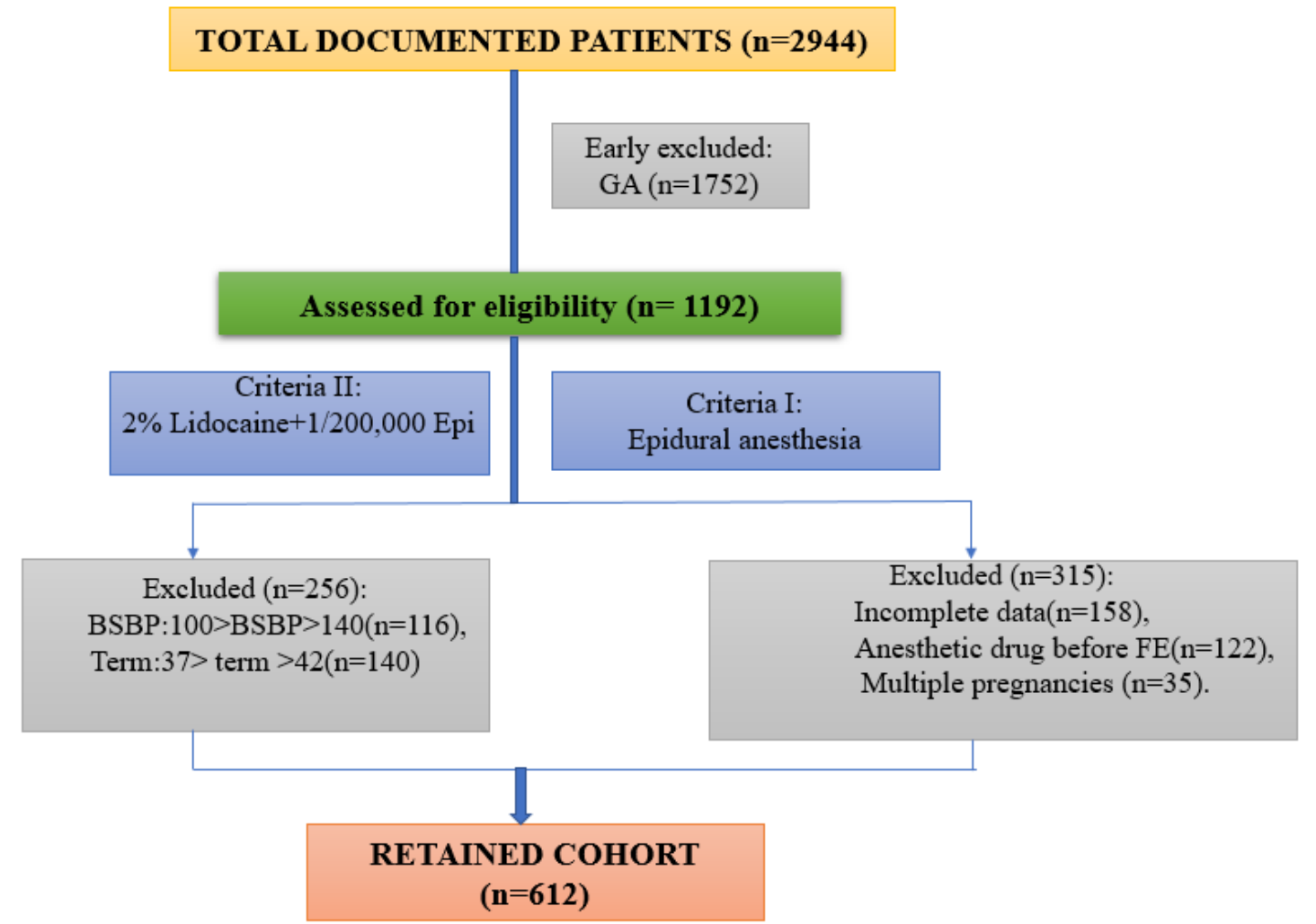

Fig.1 Flow diagram showing how we came up to the last eligible number of patients 
The variables involved in our data collection are expressed as follow:

Table 1. Descriptive statistics of data included in study [ $n=612]$

\begin{tabular}{lcc}
\hline Variable & Mean \pm SD & Median (min, max) \\
\hline Age (year) & $32.24 \pm 4.13$ & $32(23,47)$ \\
Maternal body weight $(\mathrm{kg})$ & $69.83 \pm 9.15$ & $69(48,110)$ \\
Maternal height(cm) & $158.62 \pm 4.798$ & $158(139,176)$ \\
BMI (kg/m2) & $27.39 \pm 3.4$ & $27.2(17.8,43)$ \\
ASA I: II: III (\%) & $0.98: 97.55: 1.47$ & - \\
Height (cm) & $158.62 \pm 4.798$ & $158(139,176)$ \\
BSBP (mm hg) & $117.217 \pm 9.19$ & $118(100,140)$ \\
Gravidity & $2.53 \pm 1.4$ & $2(1,8)$ \\
Parity & $1.36 \pm 0.65$ & $1(0,5)$ \\
Term (weeks) & $38.912 \pm 0.97$ & $39.07(37,41.4)$ \\
Duration of surgery(min) & $42.58 \pm 11.27$ & $40(20,110)$ \\
Estimated blood loss(ml) & $312.30 \pm 158.78$ & $300(100,2000)$ \\
Onset time of surgical anesthesia(min) & $9.33 \pm 4.98$ & $9(1,25)$ \\
Total dose of local anesthetic (LA):ml & $12.19 \pm 1.446$ & $12(8,20)$ \\
Sensory block height (thoracic dermatomal) & - & $8(11,6)$ \\
\hline
\end{tabular}

Table 2: Baseline characteristics of categorical socio-demographic data of parturient

\begin{tabular}{|c|c|c|c|c|c|c|c|}
\hline \multirow[t]{2}{*}{ Variables } & \multirow[t]{2}{*}{ Categorization } & \multirow[t]{2}{*}{ Number } & \multirow[t]{2}{*}{ Percent } & \multicolumn{2}{|c|}{ Hypotension: number of } & \multicolumn{2}{|c|}{ Pain: Number of } \\
\hline & & & & Yes\%) & No(\%) & Yes $(\%)$ & No(\%) \\
\hline \multirow[t]{2}{*}{ Age(years) } & $22-35$ & 488 & 79.7 & $57(12.44)$ & $401(87.56)$ & $45(9.8)$ & $413(90.2)$ \\
\hline & $36-47$ & 124 & 20.3 & $24(15.58)$ & $130(84.42)$ & $13(8.4)$ & 141(91.6) \\
\hline Maternal & $\leq 160$ & 419 & 68.5 & $55(13.1)$ & $364(86.9)$ & $33(7.9)$ & $386(92.1)$ \\
\hline Height(cm) & $>160$ & 193 & 31.5 & $26(13.5)$ & $167(86.5)$ & $25(13)$ & $168(87)$ \\
\hline \multirow[t]{3}{*}{$\mathrm{BMI}(\mathrm{Kg} / \mathrm{m} 2)$} & $<25$ & 148 & 24.2 & $23(15.5)$ & $125(84.5)$ & $15(10.1)$ & $133(89.9)$ \\
\hline & $25-29.9$ & 344 & 56.2 & $44(12.8)$ & $300(87.2)$ & $30(8.7)$ & $314(91.9)$ \\
\hline & $\geq 30$ & 120 & 19.6 & 14(11.7) & $106(88.3)$ & $13(10.8)$ & $107(89.2)$ \\
\hline \multirow[t]{2}{*}{ Gravidity } & $\leq 2$ & 345 & 56.4 & $38(11)$ & $173(89)$ & $36(1.4)$ & $309(89.6)$ \\
\hline & $>2$ & 267 & 43.6 & $43(14.6)$ & $224(85.4)$ & $35(8.4)$ & 232(91.6) \\
\hline \multirow[t]{2}{*}{ Parity } & $\leq 1$ & 384 & 62.7 & $46(12)$ & $338(88)$ & $39(10.2)$ & $345(89.8)$ \\
\hline & $>1$ & 228 & 37.3 & $35(35)$ & 193(65) & $19(8.3)$ & $209(91.7)$ \\
\hline \multirow[t]{2}{*}{ Term(weeks) } & $<40$ & 505 & 82.5 & $74(14.7)$ & $431(85.3)$ & $47(9.3)$ & $458(90.7)$ \\
\hline & $\geq 40$ & 107 & 17.5 & $7(6.5)$ & $100(93.5)$ & $11(10.3)$ & $98(89.7)$ \\
\hline \multirow{2}{*}{$\begin{array}{l}\text { Mother body } \\
\text { weight }(\mathrm{kg})\end{array}$} & $\leq 60$ & 83 & 13.6 & $19(22.9)$ & $64(77.1)$ & $10(12)$ & $73(88)$ \\
\hline & $>60$ & 529 & 86.4 & $62(11.7)$ & $467(87.43)$ & $48(9.1)$ & $481(90.9)$ \\
\hline \multirow[t]{2}{*}{ BSBP (mmhg) } & $<120$ & 400 & 65.4 & $65(16.25)$ & $335(83.75)$ & $31(7.75)$ & $369(92.25)$ \\
\hline & $>119$ & 212 & 34.6 & $16(7.54)$ & $196(92.46)$ & $27(12.74)$ & $185(81.26)$ \\
\hline
\end{tabular}


In our study, 612 women who fulfilled our In our study, we found that the site of puncture inclusion criteria had age between 22 and 47 for epidural anesthesia was mainly L1-2 with 440 years. 419 [68.5\%] of them were ranged in $\leq 160$ [71.9\%] of frequency. The minimum total local $\mathrm{cm}$ category concerning height.

\section{Epidural anesthesia and} categorical data characteristics operative

$17 \mathrm{ml}$. The target for anesthesia level seemed to be, at least, T8 dermatomal and his categorical frequency reached $78.58 \%$ [482 cases].

Table 3: Anesthesia categorical data

\begin{tabular}{|c|c|c|c|c|c|c|c|}
\hline \multirow[t]{2}{*}{ Variables } & \multirow[t]{2}{*}{ Category } & \multirow[t]{2}{*}{ Number } & \multirow[t]{2}{*}{ percent } & \multicolumn{2}{|c|}{ Hypotension: Number of } & \multicolumn{2}{|c|}{ Pain: Number of } \\
\hline & & & & Yes (\%) & No $(\%)$ & Yes (\%) & $\mathrm{No}(\%)$ \\
\hline \multirow[t]{2}{*}{ Site of puncture } & L1-2 & 440 & 71.9 & $63(14.3)$ & $377(85.7)$ & $41(9.3)$ & $399(90.7)$ \\
\hline & $\mathrm{L} 2-3$ & 169 & 27.6 & $18(10.65)$ & $151(89.35)$ & $17(10.1)$ & $149(89.9)$ \\
\hline \multirow{2}{*}{$\begin{array}{l}\text { Total dose of } \\
\text { LA (ml) }\end{array}$} & $\leq 11$ & 114 & 18.6 & $15(13.16)$ & $95(86.84)$ & $20(17.5)$ & $90(82.5)$ \\
\hline & $>11$ & 498 & 81.4 & $66(13.25)$ & $436(86.75)$ & $38(7.6)$ & $464(92.4)$ \\
\hline \multirow{2}{*}{$\begin{array}{l}\text { Anesthesia } \\
\text { time }\end{array}$} & $\leq 10$ & 417 & 68.14 & $61(14.6)$ & $356(85.4)$ & $40(9.6)$ & $377(90.4)$ \\
\hline & $>10$ & 195 & 31.86 & $20(10.3)$ & $175(89.7)$ & $18(9.2)$ & $177(90.8)$ \\
\hline Sensory block & $\leq 8$ & 482 & 78.8 & $65(13.49)$ & $417(86.51)$ & $48(10)$ & 434(90.) \\
\hline \multirow[t]{2}{*}{ height (dermatome) } & 7 & 39 & 6.4 & $4(10.26)$ & $35(89.74)$ & $3(7.69)$ & $36(92.31)$ \\
\hline & 6 & 91 & 14.9 & $12(13.19)$ & $79(86.81)$ & $7(7.69)$ & $84(92.31)$ \\
\hline
\end{tabular}

Table 4: Operative data frequencies

\begin{tabular}{|c|c|c|c|c|c|c|c|}
\hline \multirow[t]{2}{*}{ Variables } & \multirow[t]{2}{*}{ Category } & \multirow[t]{2}{*}{ Number } & \multirow{2}{*}{$\begin{array}{l}\text { Percen } \\
t\end{array}$} & \multicolumn{2}{|c|}{ Hypotension: Number of } & \multicolumn{2}{|c|}{ Pain: Number of } \\
\hline & & & & Yes $(\%)$ & $\mathrm{No}(\%)$ & Yes (\%) & $\mathrm{No}(\%)$ \\
\hline \multirow{2}{*}{$\begin{array}{l}\text { Duration of } \\
\text { surgery(min) }\end{array}$} & $\leq 45$ & 429 & 89.5 & $45(10.5)$ & $384(89.5)$ & $43(10.0)$ & $386(90)$ \\
\hline & $>45$ & 183 & 10.5 & $36(19.7)$ & $147(80.3)$ & $18(8.2)$ & $165(91.6)$ \\
\hline \multirow{2}{*}{$\begin{array}{l}\text { Estimated } \\
\text { blood loss(ml) }\end{array}$} & $<500$ & 593 & 96.9 & $79(13.3)$ & $514(86.7)$ & $56(9.4)$ & $537(90.6)$ \\
\hline & $\geq 500$ & 19 & 3.1 & $2(10.5)$ & $17(89.5)$ & $2(10.5)$ & $17(89.5)$ \\
\hline \multirow{2}{*}{$\begin{array}{l}\text { Apgar score } \\
\text { (at } 1^{\text {st }} \text { min) }\end{array}$} & $<8$ & 0 & 0 & 0 & 0 & 0 & 0 \\
\hline & $\geq 8$ & 612 & 100 & 81 & $531(86.76)$ & 58 & $554(90.5)$ \\
\hline
\end{tabular}

Our research showed that, among 81 patients who experienced hypotension, 44 parturients had male fetus and 37 of them female fetus. 48 parturients experienced hypotension before fetal extraction whereas 33 had it after baby extraction.

With figures below, we presented the incidence of hypotension and somato-visceral pain.

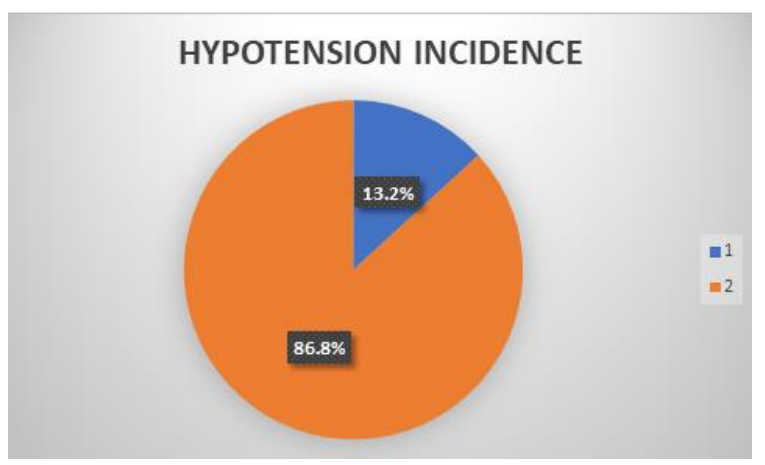

Fig.2: Hypotension rate in parturients who had elective cesarean delivery under epidural anesthesia with lidocaine $2 \%$ and epinephrine adjuvant. $1=$ Hypotension rate $2=$ No hypotension 


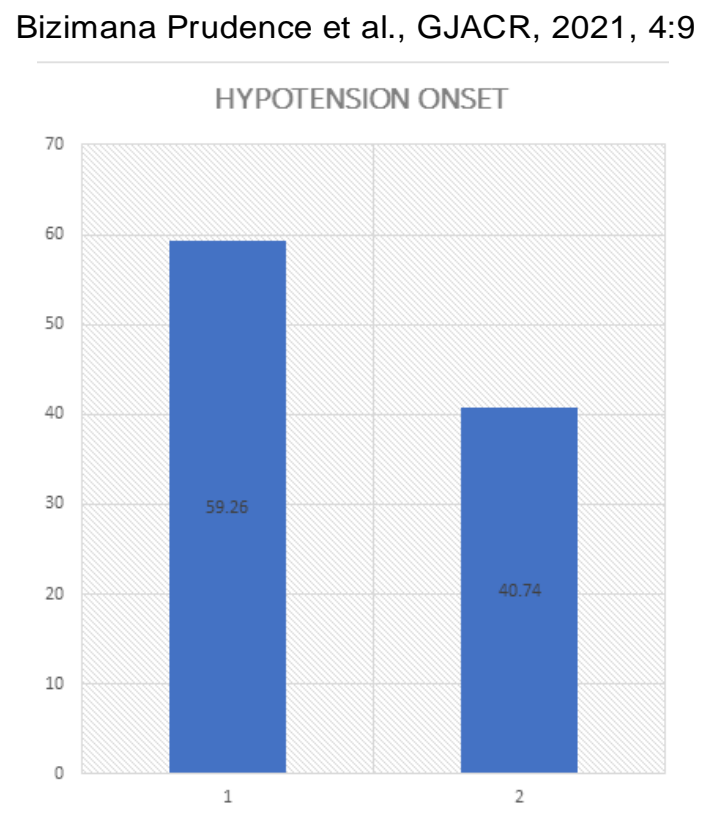

Fig3: Comparison of hypotension occurrence considering fetal extraction time: $1=59.26 \%$ : Hypotension rate before baby extraction 2=40.74\%: Hypotension rate after fetal extraction

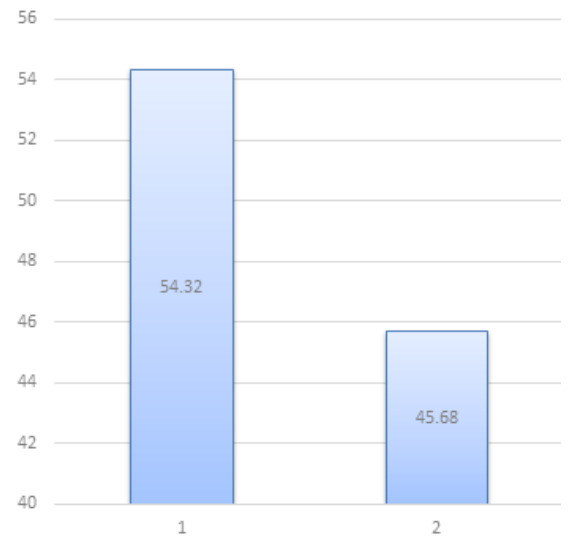

Fig.4 Comparison of hypotension rate between fetal sex:

$1=$ Hypotension rate with male fetal $2=$ Hypotension rate with female fetal

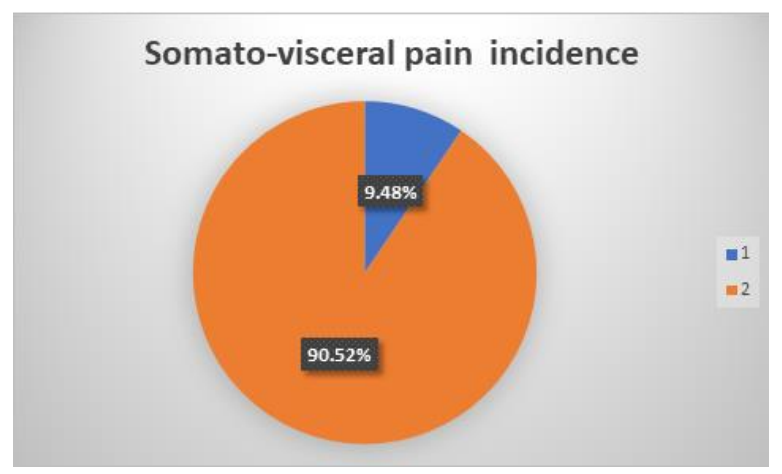

Fig.5 Incidence of somato-visceral pain within parturients who underwent cesarean section with lidocaine $2 \%$ and epinephrine as adjuvant. 1 Represents somato-visceral pain rate; 2 Represents no somato-visceral pain 
After analyzing categorical variables, we had to hypotension and somato-visceral pain during identify the risk factors associated with severe cesarean section in a univariable analysis.

Table 5. Univariate hypotension risk factors analysis

\begin{tabular}{|c|c|c|c|c|c|}
\hline \multirow[t]{2}{*}{ Variable } & \multirow[t]{2}{*}{ Group } & \multicolumn{2}{|c|}{ Hypotension } & \multirow[t]{2}{*}{ Crude OR $95 \%$ CI } & \multirow[t]{2}{*}{ P-value } \\
\hline & & Yes $(\%)$ & No $(\%)$ & & \\
\hline \multirow[t]{2}{*}{ Age(years) } & $\leq 35$ & $62(12.7)$ & $426(87.3)$ & 1 & \multirow[b]{2}{*}{0.442} \\
\hline & $>35$ & $19(15.3)$ & $105(84.7)$ & $0.804(0.461-1.403)$ & \\
\hline \multirow[t]{2}{*}{ Term (Weeks) } & $<40$ & $74(14.5)$ & $432(85.5)$ & 1 & \multirow[b]{2}{*}{0.029} \\
\hline & $\geq 40$ & $7(7.5)$ & $99(92.5)$ & $2.393(1.338-5.354)$ & \\
\hline \multirow[t]{2}{*}{ BSBP (mm hg) } & $<120$ & $65(16.3)$ & $335(83.7)$ & 1 & \multirow[b]{2}{*}{0.003} \\
\hline & $\geq 120$ & $16(7.5)$ & $196(92.5)$ & $2.377(1.338-4.223)$ & \\
\hline \multirow[t]{2}{*}{ Total dose(ml) } & $<12$ & $16(14)$ & $98(86)$ & 1 & \multirow[b]{2}{*}{0.780} \\
\hline & $\geq 12$ & $65(13.1)$ & $433(86.9)$ & $1.088(0.603-1.961)$ & \\
\hline \multirow[t]{3}{*}{ BMI (kg/m2) } & $<25$ & $23(15.5)$ & $125(84.5)$ & 1 & \\
\hline & {$[25-29,9]$} & $44(12.8)$ & $300(87.2)$ & $1.255(0.727-2.165)$ & 0.415 \\
\hline & $>29,9$ & $14(11.7)$ & $106(88.3)$ & $1.393(0.683-2.842)$ & 0.362 \\
\hline \multirow[t]{2}{*}{ Gravidity } & $\leq 2$ & $39(11.3)$ & $306(88.7)$ & 1 & \multirow[b]{2}{*}{0.109} \\
\hline & $>2$ & $42(15.7)$ & $225(84.3)$ & $0.678(0.397-1.160)$ & \\
\hline \multirow[t]{2}{*}{ Parity } & $\leq 1$ & $46(12)$ & $338(88)$ & 1 & \multirow[b]{2}{*}{0.234} \\
\hline & $>1$ & $35(15.4)$ & $193(84.6)$ & $0.750(0.467-1.205)$ & \\
\hline \multirow[t]{2}{*}{ Body weight(kg) } & $\leq 60$ & $19(22.9)$ & $64(87.1)$ & 1 & \multirow[b]{2}{*}{0.005} \\
\hline & $>60$ & $62(11.7)$ & $467(88,3)$ & $2.236(1.256-3.980)$ & \\
\hline \multirow{3}{*}{$\begin{array}{l}\text { Sensory bloc } \\
\text { height } \\
\text { (dermatomal) }\end{array}$} & 6 & $12(13.2)$ & $79(86.8)$ & 1 & \\
\hline & 7 & $4(10.3)$ & $35(89.7)$ & $1.329(0.401-4.411)$ & 0.642 \\
\hline & $\leq 8$ & $65(13.5)$ & $417(86.5)$ & $0.974(0.503-1888)$ & 0.939 \\
\hline \multirow{2}{*}{$\begin{array}{l}\text { Duration } \\
\text { surgery(min) }\end{array}$} & $\leq 45$ & $45(10.5)$ & $384(89.5)$ & 1 & \\
\hline & $>45$ & $36(19.7)$ & $147(80.3)$ & $0.479(0.297-0.772)$ & 0.002 \\
\hline \multirow{2}{*}{$\begin{array}{l}\text { Anesthesia Onset } \\
\text { time (min) }\end{array}$} & $\leq 10$ & $61(14.6)$ & $356(83.4)$ & 1 & \\
\hline & $>10$ & $20(10.3)$ & $175(99)$ & $1.499(0.877-2.564)$ & 0.137 \\
\hline \multirow{2}{*}{$\begin{array}{l}\text { Estimated blood } \\
\operatorname{loss(ml)}\end{array}$} & $<500$ & $79(13.3)$ & $514(86.7)$ & 1 & \multirow[b]{2}{*}{0.526} \\
\hline & $\geq 500$ & $2(10.5)$ & $17(89.5)$ & $1.306(0.296-5.763)$ & \\
\hline \multirow{2}{*}{$\begin{array}{l}\text { Site of puncture } \\
\text { (Dermatomal) }\end{array}$} & Ll-2 & $63(14.3)$ & $377(85.7)$ & 1 & \multirow[b]{2}{*}{0.206} \\
\hline & L2-4 & $18(10.5)$ & $154(89.5)$ & $1.430(0.820-2.494)$ & \\
\hline \multirow[t]{2}{*}{ Height(cm) } & $\leq 160$ & $50(13.3)$ & $325(86.7)$ & 1 & \\
\hline & $>160$ & $26(13.5)$ & $167(86.5)$ & $0.971(0.588-1.602)$ & 0.907 \\
\hline
\end{tabular}

In order to determine factors associated with severe hypotension during CS, we performed a multivariate analysis of variables via a multiple logistic regression.

The EPA for elective CD in our study was performed with $2 \%$ lidocaine and $1 / 200000$ epinephrine as additive. The site of epidural puncture was L1-2 [71.9\%] and L2-3 [27.6\%], in lateral position for all parturients with essentially paramedian approach, and without any prophylactic vasopressor agent reported. 
Table 6: Multivariate analysis showing relevant factors associated with severe hypotension

\begin{tabular}{|c|c|c|c|c|c|c|}
\hline \multirow[t]{2}{*}{ Variable } & \multirow[t]{2}{*}{ Grouping } & \multicolumn{2}{|c|}{ Hypotension, no of: } & \multirow[t]{2}{*}{ COR 95\%CI } & \multirow[t]{2}{*}{ AOR95\%CI } & \multirow[t]{2}{*}{ P-Value } \\
\hline & & Yes $(\%)$ & No(\%) & & & \\
\hline \multirow{2}{*}{$\begin{array}{l}\text { BSBP } \\
\text { (mmhg) }\end{array}$} & $<120$ & $65(16.3)$ & $335(85.5)$ & 1 & 1 & \\
\hline & $\geq 120$ & $16(7.5)$ & $196(83.7)$ & $2.392(1.346-4.252)$ & $2.377(1.338-4.223)$ & 0.003 \\
\hline \multirow{2}{*}{$\begin{array}{l}\text { Mother body } \\
\text { weight(kg) }\end{array}$} & $\leq 60$ & $19(22.9)$ & $64(87.1)$ & 1 & 1 & \\
\hline & $>60$ & $62(11.7)$ & $467(88.3)$ & $2.233(1.254-3.975)$ & $1.236(1.256-3.980)$ & 0.005 \\
\hline \multirow{2}{*}{ Term(weeks) } & $<40$ & $74(14.6)$ & $432(85.5)$ & 1 & 1 & \\
\hline & $\geq 40$ & $7(7.5)$ & $99(92.5)$ & $2.393(1.338-5.354)$ & $2.091(0.976-4.480)$ & 0.026 \\
\hline \multirow{2}{*}{$\begin{array}{l}\text { Duration of } \\
\text { surgery(min) }\end{array}$} & $\leq 45$ & $45(10.9)$ & $384(88.3)$ & 1 & 1 & \\
\hline & $>45$ & $36(19.7)$ & $147(83.1)$ & $0.479(0.297-0.772)$ & $0.480(0.297-0.774)$ & 0.002 \\
\hline
\end{tabular}

\section{DISCUSSION}

In our study, for the primary endpoint, 81parturients [13.2\%] experienced severe hypotension. Its distribution considering fetal extraction time showed a tendency of higher incidence before than after baby extraction period with $59.26 \%$ and $40.74 \%$ rates of the allhypotension cases respectively, while parturients with male fetus were more likely to get hypotension than mother with female baby [54.32\% vs $45.68 \%$ ]. Our finding is very close to the results of Chantal $\mathrm{T}$. Crochetière et al who found a hypotension rate of $13.6 \%{ }^{[32]}$. However, our result is different from some findings in previous studies [33] that found $72 \%, 36 \%, 40 \%$ with sitting, right lateral, and left lateral patients' position, respectively. Using the same LA and hypotension criteria, but in sitting position during epidural puncture, E. Bjornestad et al ${ }^{[29]}$ found a hypotension incidence of $75 \%$, and $50 \%$ with 2-chroroprocaine in epidural-use. Lateral position results in little vagal reflex and thus decreased hypotension rate. This view is supported by Fuyi Shen et al and Obasuyi and co-authors ${ }^{[30,33]}$ who claimed a little hypotension rate with lateral position in ropivacaine combined epidural- spinal and bupivacaine spinal anesthesia for CS. With the same hypotension criteria like in our study, a SA study ${ }^{[28]}$ resulted in more than $71 \%$ of hypotension incidence. Behind lateral decubitus position, we speculate also on the level of sensory block to influence hypotension incidence. In fact, a sensory block level presumably targeted at T8 $[78.58 \%$ of frequencies] in our study resulted in least hypotension rate compared to the findings of other studies, without any exacerbation in pain incidence. Previous findings' research [2,28] agreed with us. Our findings showed that BSBP, Maternal weight, pregnancy age, and duration of surgery were variables associated with hypotension during CD. Mothers with a BSBP < $120 \mathrm{mmhg}$ has more than a 2-fold of developing severe hypotension compared to mothers with $\mathrm{BSBP} \geq 120$ [p $=0.003, \mathrm{AOR}=2.38[95 \% \mathrm{Cl}$ : 1.34-4.22]. The explanation is that parturients with BSBP above 120mmhg and under $140 \mathrm{mmhg}$ has physiologically, stable vascular smooth muscle, therefore devoid of hyperactivity with a systemic vascular resistance and then a high safety margin. This argument is supported by other similar studies [2,34]. Parturients with body weight $\leq 60 \mathrm{~kg}$ developed also severe hypotension during surgery than parturients above 60kg $[\mathrm{p}=0.005, \mathrm{AOR}=1.24$ [95\%Cl:1.263.98]]. When using other LAs, study [35] said that high BMI increased the likelihood of developing severe hypotension. The reasons of this discrepancy may be linked to the difference in LA, parturient position and site of puncture adopted. Our study revealed that patients with pregnancy aged below 40 weeks were much affected by hypotension than parturients with 
pregnancy aged 40 weeks or above [ $p=0.026$, $\mathrm{AOR}=2.091[95 \% \mathrm{Cl}: 0.976-4.480]]$. When the duration of surgery went over 45 minutes, the likelihood of having hypotension was also increased $[p=0.002$, AOR=0,480 [0.297-0.774]. We speculate on the continuous bleeding as the surgery takes a long time, and this clinical situation has no more auto- compensatory mechanism as the endogenous catecholamines are no longer available. Even though not statistically significant; age $>35$, gravidity $>2$, multiparity and an anesthesia onset time $\leq 10$ min were more likely to be associated with hypotension. We claim that, clinically, this may be very important because it is an added value which can lighten anesthesiologists when thinking about prophylactic measurements, especially for no modifiable risk-factors.

Our study showed a somato-visceral pain incidence of $9.47 \%$ including one case that underwent a GA with endotracheal intubation, for having an excruciating pain after fetal extraction. Pain rate in our study is close to the findings of a study ${ }^{[36]}$ that used lidocaine with 3 additives supposedly to improve the quality of analgesia during surgery, but better compared to $3 \%$ chloroprocaine results. Welker et $\mathrm{Al}^{[37]}$ found a visceral pain rate of $17 \%$ when EPA was performed with bupivacaine in lateral decubitus position. E. Bjornestad and coworkers ${ }^{[29]}$ found $20 \%$ and $30 \%$ of visceral pain in their study with epidural lidocaine and epidural 2-chloroprocaine respectively, while Yicheng Yang and colleagues [38] found an intraoperative pain incidence ranged at $70 \%$ and $47.5 \%$ respectively in epidural ropivacaine-morphine and epidural ropivacaine- morphinedexmedetomidine. It is actually known that epinephrine has some properties of antinociceptive and enhances the duration of analgesia used together with LAs [39,40]. Furthermore, recent researches by Aliza Olapour et al ${ }^{[41]}$ said that lidocaine's sensory and motor block were superior to the Ropivacaine's, and epinephrine was found to exert an essential role ${ }^{[39]}$. Moreover, Meechan and co-authors ${ }^{[42]}$ let know that anesthesia effects of ropivacaine in their study were inferior to those with lidocaine- epinephrine. A fresh clinical research in Japan ${ }^{[43]}$ support the idea that the more cephalad the epidural catheter is placed, the more the quality of analgesia is, but did not find any difference between epidural catheter placement inT10-11 and T11-12 in post-cesarean section for pain relief. The same study considered that the LA injected via lumbar dermatomes for CS may not provide sufficient analgesia in the lower thoracic dermatome. Based on our findings and the results of this Japanese research's result, we concluded that the reasons of lower pain incidence in our study include the site of puncture mainly in L1-2 interspace in our study. It seems that the optimum pain relief is obtained when epidural catheter is placed between the highest lumbar and lowest thoracic dermatomal. In our study, the enregistered pain cases were correlated with both lower given total dose and the highest height of the parturients. So, we suggest a cut off for LA in this area. Our results showed that the dose between 12 to $17 \mathrm{ml}$ was safe [did not induce neither high rate of hypotension nor fetuses abnormal Apgar score]. Early, a study showed that a total dose of $23 \mathrm{ml}$ of $2 \%$ lidocaine with epinephrine, resulted only in $13.6 \%$ of hypotension rate without any sign of toxicity [32]. A research ${ }^{[36]}$ used more than $23 \mathrm{ml}$ in lidocaine with epinephrine bicarbonate and fentanyl as additives resulted in $12 \%$ of pain incidence. Natan Weksler et al demonstrated how the increased dose of bupivacaine from $7.5-10 \mathrm{mg}$ to $10-12.5 \mathrm{mg}$ decreased the pain rate from $75 \%$ to $31.6 \%$. Therefore, $12 \mathrm{ml}$ of $2 \%$ lidocaine with epinephrine can be recommended as a minimum dose, but other studies are necessary to determine the ideal dose of LA needed with various heights of mothers. Our view is supported by Xiangqi di et al ${ }^{[22]}$ who suggested the fixation of ideal dose considering the maternal height, and Yasui et $\mathrm{Al}{ }^{[44]}$ in his SA study went beyond, proposing a dosage of LAs based on both height and weight. 
In our study, the anesthesia onset time mean was $9.33 \mathrm{~min}$ with a minimum/maximum of $1 / 25 \mathrm{~min}$. This result is close to the findings of other studies with $9.3 \mathrm{~min}$ when $2 \%$ lidocaine was added to epinephrine, bicarbonate and fentanyl, $10.9 \mathrm{~min}$ for $3 \%$ chloroprocaine [36] and 8min [min and max 2-22min] in lidocaine $2 \%$ and epinephrine [29]. A recent wide array of systematic review ${ }^{[45]}$ conducted in USA that compared six LAs mainly used in epidural anesthesia for CS has concluded that lidocaine $2 \%$ with bicarbonate has the quickest anesthesia onset followed by 2-chloroprocaine and lidocaine $2 \%$ without additive, but this second LA was found to be associated with a highest hypotension rate ${ }^{[45]}$. $3 \%$ chloroprocaine with epinephrine compared to $2 \%$ lidocaine with epinephrine showed ${ }^{[46]}$ a long duration and best surgical analgesia with lidocaine $2 \%$ and epinephrine. Through these findings, we deduce that lidocaine $2 \%$ is a best choice for epidural elective $C D$, all the more so, if epinephrine was added on it ${ }^{[4]}$. The advantages of using lidocaine in EPA for CD include his quick anesthesia onset, thereby avoiding GA and threaten side effectsassociated, when occurring. This allows epidural lidocaine- use even in some emergence cases. Our idea is strongly supported by Bjornestad et al ${ }^{[29]}$ who concluded that emergency may not exclude the use of epidural lidocaine, but, considering his anesthesia onset unpredictability, we suggest a preliminary study who can identify risk-factors associated with it. We believe that any useful peri-anesthesia refinement, however minimal, is likely to yield substantial advantages by saving lives.

In our study no newborn was found distressed at $1^{\text {st }}, 5^{\text {th }}$ and $10^{\text {th }}$ min, 3 newborns had 8 as Apgar score but had already become 10 at 5 th min. Our results are similar to those of Chantal $T$. Crochetière and coworkers [32]. Other researchers have considered abnormal Apgar score or acidosis with Apgar score $<7[27,38,47,48]$. In their study for epidural anesthesia, comparing ropivacaine and bupivacaine effects for scheduled CS, Sandra Kampe et al ${ }^{[27]}$ found some cases of neonates with Apgar score less than 7. A study on SA with bupivacaine [47] showed an acidosis rate in neonates of $3.4 \%$.

Limitations: Researches on factors associated with hypotension during CS under epidural lidocaine with epinephrine, are until now so scarce, this limited our results interpretation and comparison regarding this setting. The lack of consensus for hypotension criteria ${ }^{[8]}$ reflected by heterogeneity of found hypotension rates, probably hampers the reliability of many observational studies in this area. First Affiliated hospital of CQMU, being a teaching hospital means that several cases of EPA are performed by trainee physicians in anesthesiology. This situation may be a source of bias by increasing the rate of hypotension as a study [2] revealed it [the anesthesiologist's experience was risk factor of increased hypotension rate]. Some data were abandoned because of incompleteness and anesthetic drugs injected before fetal extraction due, presumably to inadequate insertion of epidural catheter, which may be attributed to the inexperience of the resident physicians in training.

Conclusion: Our study found a hypotension incidence of $13.2 \%$ whereas $\mathrm{BSBP}<120 \mathrm{mmhg}$, gestational age < 40 weeks, maternal body weight $\leq 60 \mathrm{~kg}$ and surgery duration above $45 \mathrm{~min}$ were relevant factors associated with severe hypotension. These findings dissuade some anesthesia providers who could think that every epidural anesthesia does not need prophylactic vasopressors. In elective CS, not only Lidocaine $2 \%$ can be preferred for being less toxic, but also, it offered in our study the best outcomes: the incidences of hypotension and somato-visceral pain, the onset time of surgical anesthesia and the clinical condition of newborns were relatively better in our study with, then, a superior efficacy and safety profile compared to the findings of similar previous studies with other LAs. We think that these outcomes could undergo a slight change if all limitations or weakness observed were removed. Hypotension rate may also change by the modification of hypotension 
criteria. Whether the noted benefits can be assigned to the effects' synergy of all anesthetic conditions [epidural puncture site, parturient position, approach and targeted sensory block height] or to only some of them, beside the used LA and additive in our study, must be clarified and upheld by further investigations.

\section{ACKNOWLEDGEMENTS}

We would like to acknowledge Drs Laurent, Astère and Issa Isouffu for their technical support and language edition.

\section{Supplementary material}

STROBE_checklist statment_2020.pdf

Interest conflict: None

Disclaimer: The view in this study is authors' own findings not a position of any institution or any individual personality.

\section{Source of funding support: None REFERENCES}

[1]. Shokrpour M, Reza PPS, Sharifi M, Kamali A. Prevalence of Cesarean Section and Analysis of Neonatal Apgar Score and the Mean Time of Second Phase of Labor in Pregnant Women. Med Arch [Sarajevo, Bosnia Herzegovina]. 2019;73 [6]:399-403.

[2]. Shitemaw T, Jemal B, Mamo T, Akalu L. Incidence and associated factors for hypotension after spinal anesthesia during cesarean section at Gandhi Memorial Hospital Addis Ababa, Ethiopia. PLoS One [Internet]. 2020;15 [8 August]:1-11. Available from: http://dx.doi.org/10.1371/journal.pone.0236755

[3]. Chumpathong S, Chinachoti T, Visalyaputra $S$, Himmunngan $\mathrm{T}$. Incidence and risk factors of hypotension during spinal anesthesia for cesarean section at Siriraj Hospital. J Med Assoc Thail. 2006;89 [8]:1127-32.

[4]. Tharwat AA, Yehia AH, Wahba KA, Ali AEG. Efficacy and safety of post-cesarean section incisional infiltration with lidocaine and epinephrine versus lidocaine alone in reducing postoperative pain: A randomized controlled double-blinded clinical trial. J Turkish Ger Gynecol Assoc. 2016;17 [1]:1-5.

[5]. Dusitkasem S, Herndon BH, Somjit M, Stahl DL, Bitticker E, Coffman JC. Comparison of phenylephrine and ephedrine in treatment of spinal-induced hypotension in high-risk pregnancies: A narrative review. Front Med. 2017;4 [JAN]:1-8.

[6]. Christelis N, Harrad J, Howell PR. A comparison of epidural ropivacaine $0.75 \%$ and bupivacaine $0.5 \%$ with fentanyl for elective caesarean section. Int J Obstet Anesth. 2005;14 [3]:212-8.

[7]. Waldinger R, Weinberg G, Gitman M. Local Anesthetic Toxicity in the Geriatric Population. Drugs and Aging [Internet]. 2020;37 [1]. Available from: https://doi.org/10.1007/s40266019-00718-0

[8]. KIÖhr S, Roth R, Hofmann T, Rossaint R, Heesen M. Definitions of hypotension after spinal anaesthesia for caesarean section: Literature search and application to parturients. Acta Anaesthesiol Scand. 2010;54 [8]:909-21.

[9]. Chen Y, Yan L, Zhang Y, Yang X. The role of DRP1 in ropivacaine-induced mitochondrial dysfunction and neurotoxicity. Artif Cells, Nanomedicine Biotechnol [Internet]. 2019;47 [1]:1788-96. Available from: https://doi.org/10.1080/21691401.2019.159485 8

[10]. Wohlrab P, Boehme S, Kaun C, Wojta J, Spittler A, Saleh L, et al. Ropivacaine activates multiple proapoptotic and inflammatory signaling pathways that might subsume to trigger epidural-related maternal fever. Anesth Analg. 2020;130 [2]:321-31.

[11]. Haileselassie B, Joshi AU, Minhas PS, Mukherjee R, Andreasson KI, Mochly-Rosen D. Mitochondrial dysfunction mediated through dynamin-related protein 1 [Drp1] propagates impairment in blood brain barrier in septic encephalopathy. J Neuroinflammation. 2020;17 [1]:1-11.

[12]. El-Boghdadly K, Pawa A, Chin KJ. Local anesthetic systemic toxicity: Current perspectives. Local Reg Anesth. 2018;11:35-44.

[13]. Pratt S, Hess P, Vasudevan A. A prospective randomized trial of lidocaine $30 \mathrm{mg}$ versus 45 $\mathrm{mg}$ for epidural test dose for intrathecal injection in the obstetric population. Anesth Analg. 2013;116 [1]:125-32.

[14]. Dun-Chi Lin J, Sivanesan E, Horlocker TT, Missair A. Two for One: A Case Report of Intravenous Lipid Emulsion to Treat Local Anesthetic Systemic Toxicity in Term Pregnancy. A A case reports. 2017;8 [9]:235-7.

[15]. Macfarlane AJR, Gitman M, Bornstein KJ, ElBoghdadly K, Weinberg G. Updates in our understanding of local anaesthetic systemic 
toxicity: a narrative review. Anaesthesia. 2021;76 [S1]:27-39.

[16]. Chooi C, Cox JJ, Lumb RS, Middleton P, Chemali M, Emmett RS, et al. Techniques for preventing hypotension during spinal anaesthesia for caesarean section. Cochrane Database Syst Rev. 2020;2020 [7].

[17]. Atashkhoei S, Abedini N, Pourfathi H, Znoz AB, Marandi $\mathrm{PH}$. Baricity of bupivacaine on maternal hemodynamics after spinal anesthesia for cesarean section: A randomized controlled trial. Iran J Med Sci. 2017;42 [2]:136-43.

[18]. Okucu F, Aksoy M, Ince I, Aksoy AN, Dostbıl A, Ozmen O. Combined spinal epidural anesthesia in obese parturients undergoing cesarean surgery. Anaesthesist. 2021; [January].

[19]. Massoth C, Chappell D, Kranke P, Wenk M. Supine hypotensive syndrome of pregnancy $A$ review of current knowledge. 2021;1-8.

[20]. Jelting Y, Klein C, Harlander T, Eberhart L, Roewer N, Kranke P. Preventing nausea and vomiting in women undergoing regional anesthesia for cesarean section : challenges and solutions. 2017;83-90.

[21]. Singh PM, Singh NP, Reschke M, Kee WDN, Palanisamy A, Monks DT. Vasopressor drugs for the prevention and treatment of hypotension during neuraxial anaesthesia for Caesarean delivery : a Bayesian network meta-analysis of fetal and maternal outcomes. $\mathrm{Br} \mathrm{J}$ Anaesth [Internet]. 2020;124 [3]:e95-107. Available from: https://doi.org/10.1016/j.bja.2019.09.045

[22]. Yu X, Zhang F. The effect of parturient height on the median effective dose of intrathecally administered ropivacaine. Ann Saudi Med. 2016;36 [5]:328-33.

[23]. Wang X, Zhou F. Maternal Position and Development of Hypotension in Patients undergoing Cesarean Section under Combined Spinal- Epidural Anesthesia of Intrathecal Hyperbaric Ropivacaine. 2015;52-8.

[24]. Lamon AM, Habib AS. Managing anesthesia for cesarean section in obese patients: Current perspectives. Local Reg Anesth. 2016;9:45-57.

[25]. Tsen LC. Anesthesia for cesarean delivery. Essent Clin Anesth. 2011; [6]:751-6.

[26]. Kampe S, Tausch B, Paul M, Kasper SM, Bauer $\mathrm{K}$, Diefenbach $\mathrm{C}$, et al. Epidural block with ropivacaine and bupivacaine for elective caesarean section: Maternal cardiovascular parameters, comfort and neonatal well-being. Curr Med Res Opin. 2004;20 [1]:7-12.
[27]. Chen Y, Yan L, Zhang Y, Yang X, Singer M, Chooi $C$, et al. Choice of local anaesthetic for epidural caesarean section: a Bayesian network meta-analysis. Virulence [Internet]. 2017;20 [1]:254-9. Available from: http://dx.doi.org/10.1038/jp.2016.207

[28]. Thomard P, Morakul S, Wirachpisit N, Ittichaikulthol W, Pisitsak C. Relationship between Abdominal Circumference and Incidence of Hypotension during Cesarean Section under Spinal Anesthesia. Anesthesiol Res Pract. 2020;2020.

[29]. Bjørnestad E, Iversen OLEE, Raeder J. Similar onset time of 2-chloroprocaine and lidocaine + epinephrine for epidural anesthesia for elective Cesarean section. Acta Anaesthesiol Scand. 2006;50 [3]:358-63.

[30]. Obasuyi BI, Fyneface-Ogan S, Mato CN. A comparison of the haemodynamic effects of lateral and sitting positions during induction of spinal anaesthesia for caesarean section. Int $\mathrm{J}$ Obstet Anesth [Internet]. 2013;22 [2]:124-8. Available from: http://dx.doi.org/10.1016/j.ijoa.2012.12.005

[31]. Xiao F, Shen B, Xu WP, Feng Y, Ngan Kee WD, Chen XZ. Dose-Response Study of 4 WeightBased Phenylephrine Infusion Regimens for Preventing Hypotension During Cesarean Delivery Under Combined Spinal-Epidural Anesthesia. Anesth Analg. 2020;130 [1]:187-93.

[32]. Crochetière CT, Trépanier CA, Coté JJ. Epidural anaesthesia for Caesarean section: comparison of two injection techniques. Can $\mathrm{J}$ Anaesth. 1989;36 [2]:133-6.

[33]. Xu Z, Shen F, Zhang Y, Tao Y, Chen X, Liu Z. Combined spinal-epidural anesthesia with hypobaric ropivacaine in sitting position significantly increases the incidence of hypotension in parturients undergoing cesarean section. J Obstet Gynaecol Res. 2017;43 [4]:669-75.

[34]. Heesen M, Hilber N, Rijs K, Rossaint R, Girard $\mathrm{T}$, Mercier FJ, et al. A systematic review of phenylephrine vs . noradrenaline for the management of hypotension associated with neuraxial anaesthesia in women undergoing caesarean section. 2020;800-8.

[35]. Gaiser R. Anesthetic considerations in the obese parturient. Clin Obstet Gynecol. 2016;59 [1]:193-203.

[36]. Sharawi N, Bansal P, Williams M, Spencer $H$, Mhyre JM. Comparison of Chloroprocaine Versus Lidocaine with Epinephrine, Sodium 
Bicarbonate, and Fentanyl for Epidural Extension Anesthesia in Elective Cesarean Delivery: A Randomized, Triple-Blind, Noninferiority Study. Anesth Analg. 2021;132 [3]:666-75.

[37]. Unit PC, Unit OA. Comparison of Visceral Pain Incidence during Cesarean Section Performed under Spinal or Epidural Anesthesia.

[38]. Yang Y, Song C, Song C, Li C. Addition of dexmedetomidine to epidural morphine to improve anesthesia and analgesia for cesarean section. Exp Ther Med. 2020;1747-54.

[39]. Katz D, Hamburger J, Gutman D, Wang R, Lin $H M$, Marotta $M$, et al. The effect of adding subarachnoid epinephrine to hyperbaric bupivacaine and morphine for repeat cesarean delivery: A double-blind prospective randomized control trial. Anesth Analg. 2018;127 [1]:171-8.

[40]. Kim H, Hwang K, Yun SM, Kim DJ. Usage of Epinephrine Mixed With Lidocaine in Plastic Surgery. J Craniofac Surg. 2020;31 [3]:791-3.

[41]. Olapour A, Akhondzadeh R, Rashidi M, Gousheh M, Homayoon R. Comparing the effect of bupivacaine and ropivacaine in cesarean delivery with Spinal anesthesia. Anesthesiol Pain Med. 2020;10 [1]:1-6.

[42]. Fujita K, Sunada K. Effect of epinephrine on the distribution of ropivacaine and lidocaine using radioactive isotopes in rat maxilla and pulp. Odontology [Internet]. 2021;109 [1]:168-73. Available from: https://doi.org/10.1007/s10266020-00536-6

[43]. Murata Y, Yamada K, Hamaguchi Y, Yamashita S, Tanaka M. An optimal epidural catheter placement site for post-cesarean section analgesia with double-space technique combined spinal-epidural anesthesia: a retrospective study. JA Clin Reports. 2021;7 [1].

[44]. YASUI S. Cesarean section. Jpn J Med Sci Biol. 1963;49:1036-40.

[45]. Reschke MM, Monks DT, Varaday SS, Ginosar Y, Palanisamy A, Singh PM. Choice of local anaesthetic for epidural caesarean section: a Bayesian network meta-analysis. Anaesthesia. 2020;75 [5]:674-82.

[46]. Feng SW, Cao Y, Wang WG, Liu YS, Shen XF. Addition of adrenaline to chloroprocaine provides a moderate duration time for epidural anaesthesia in elective caesarean section. $\mathrm{J}$ Int Med Res. 2012;40 [3]:1099-107.

[47]. Knigin D, Avidan A, Weiniger CF. The effect of spinal hypotension and anesthesia-to-delivery time interval on neonatal outcomes in planned cesarean delivery. Am J Obstet Gynecol [Internet]. 2020;223 [5]:747.e1-747.e13. Available from: https://doi.org/10.1016/j.ajog.2020.08.005

[48]. Imani F, Entezary SR, Alebouyeh MR, Parhizgar $S$. The maternal and neonatal effects of adding tramadol to $2 \%$ lidocaine in epidural anesthesia for cesarean section. Anesthesiol Pain Med. 2011;1 [1]:25-9. 